\title{
Dynamic Pricing Strategy based on the Competitors-referenced for Fresh Goods in E-commerce
}

\author{
Lina $\mathrm{CHANG}^{1, \text { a }}$, Fuhui JING ${ }^{2, \mathrm{~b}}$, Hong WANG ${ }^{3, \mathrm{c}}$ \\ ${ }^{1}$ School of Management, Qingdao Huanghai University, Qingdao, 266427, China \\ ${ }^{2}$ School of Management, Qingdao Huanghai University, Qingdao, 266427, China \\ ${ }^{3}$ School of Management, Qingdao Huanghai University, Qingdao, 266427, China \\ aemail: changlina1111@163.com, bemail: jingfuhui2007@163.com, 'email:wh201209@163.com
}

Keywords: Electricity Suppliers, Fresh Goods, Product Selection, Dynamic Pricing

\begin{abstract}
In recent years, it becomes a hot spot in the e-commerce industry that electricity suppliers involved in the fresh goods in China. The uniqueness of the products they sell makes the development of fresh electricity suppliers become a topic worth studying. Due to the status quo, established the pricing models of fresh goods in electricity suppliers, competitors-referenced method is introduced to dynamic pricing of fresh electricity suppliers. Hope to improve the market competitiveness of e-commence suppliers through reasonable pricing.
\end{abstract}

\section{Introduction}

The number of e-commerce platform related agriculture in China is more than 30,000 at present, and about 3,000 of them engaged in trading of agricultural products[1]. However, these e-commerce engaged in agricultural products are in the loss-leader operating state, so large e-commence are trying to entering new fields to avoid the fierce market competition, especially the hot fresh goods business. In May 2014, a batch of electricity enterprise such as the SFBest, the Too Too, and the Tmall, launched a series of promotion activities including "trying to taste litchi”, "free send litchi”, and "open to booking cherries", which made the competition among the enterprises became increasingly fierce.The average profit of fresh goods business of e-commence is about 30\% 40\%, far higher than that of clothing, home appliances, toys, snacks, and so on. As the degree of market concentration increasing day by day, multiple competition has been formed, which resulted in the trend of low profit rate of this unit. In this case, the pricing strategy of fresh goods send in e-commence become extremely urgent and important. E-commence suppliers operate fresh goods establish a scientific, objective and reasonable method of dynamic pricing, can not only improve its operating profit and expanding market scope, but also has important practical significance in improving the overall efficiency and benefit of electricity industry.

\section{Literature Review}

Chan[2] and Yano[3] reviewed the dynamic pricing model from the perspective of combine pricing with inventory decision-making and with material procurement; J.K.Giger[4] built the dynamic pricing model for agricultural products logistics, analysis the model in different cases, and pointed out the method to realize minimum logistics cost.

L.Wang[5]constructed the retailers' pricing model for fresh agricultural product, studied the 
consumers' choices based on price and freshness; L.Tang[6] considered the consumer behavior when construct the dynamic pricing model for fresh agricultural products. Y.J.Lu put forward the pricing model for fresh vegetables in supermarket based on value loss of fresh goods; F.Wang[8] studied the dynamic pricing strategy of supermarkets, to build the dynamic pricing model, and compared the two kinds of model and analysis an example.

Comprehensive literature both at home and abroad, the research of dynamic pricing model for fresh goods is mainly aimed at the supermarkets or stores, barely concerning the e-commence style, what's more, that's quite infrequent to use the pricing method based on competitors-referenced for e-commence suppliers. Through analysis of the current operation of fresh goods in e-commence suppliers, the dynamic pricing model is established, in order to improve the payoffs of e-commence supplier in fresh goods business, to enhance the competitiveness of e-commence suppliers in fresh goods business.

\section{Dynamic Pricing Model for Fresh Agricultural Products in E-commence}

Dynamic Pricing Model Base on the Competitors-referenced. Competitors-referenced pricing is a pricing method based on competitors' price, the pricing model is expressed as the following linear function:

$\omega_{h, a}=\sum_{r=1}^{k} \tau_{h, r} \omega_{h, r}\left(1-\delta_{a, r}\right)$

Among them, $h$ represents products, $h=1,2, \ldots, \mathrm{g} ; r$ represents the competitors of e-commence supplier $a, r=1,2, \ldots, \mathrm{k} ; \omega_{h, a}$ represents the price of $h$ in e-commence supplier $a$; $\omega_{h, r}$ represents the price of $h$ in competitor $r ; \tau_{h, r}$ represents the weights of competitors; $\delta_{a, r}$ represents the difference between competitor $r$ and e-commence supplier $a$ in price impression.

Price impression refers to the perception of consumers to overall price level of stores (including farming markets, supermarkets, e-commence suppliers, etc). Here in the following way (function (2)) to calculate $\delta_{a, r}$ :

$$
\delta_{a, r}=\sum_{h=1}^{g}\left(\omega_{h, r} / \omega_{h, a}\right)\left(q_{h, r} / \sum_{h=1}^{g} q_{h, a}\right)-1
$$

In this function, $q_{h, r}$ represents the sales volume of product $h$ in competitor $r ; q_{h, a}$ represents the sales volume of product $h$ in e-commence supplier $a$.

Using function (1), e-commence supplier a can determine the upper bound $\left(\bar{\omega}_{h, a}^{(i)}\right)$ of price in fresh goods business based on competitors-referenced model $\bar{\omega}_{h, a}^{(i)}$ :

$$
\bar{\omega}_{h, a}^{(i)}=\sum_{r=1}^{k} \tau_{h, r} \bar{\omega}_{h, r}^{(i)}\left(1-\delta_{a, r}\right)
$$

$\bar{\omega}_{h, a}^{(i)}$ is the optimal price of e-commence supplier $a$ on fresh good $h$ in stage $i$, denoted by $\omega_{i}^{*}$ :

$\omega_{i}^{*}=\bar{\omega}_{h, a}^{(i)}$

Division of Competitors. After calculating the value of $\delta_{a, r}$, to measure the competition degree of product $h$ in fresh goods industry, and to formulate reasonable price position, e-commence supplier $a$ need to consider $\delta_{a, r}$ further more. After determining the e-commence supplier's own 
price impression, there are a pair of threshold value $\delta_{1}$ and $\delta_{2},-\infty<\delta_{1}<\delta_{2}<+\infty$ : if $\delta_{a, r}<\delta_{1}$, then competitor $r$ is low price impression; if $\delta_{1} \leq \delta_{a, r} \leq \delta_{2}$, then competitor $r$ is medium price impression; if $\delta_{a, r}>\delta_{2}$, then competitor $r$ is high price impression, shown in table 1 .

Table 1 Division of Competitors

\begin{tabular}{|c|c|}
\hline Price Impression $\delta_{a, r}$ & Competitor $r$ \\
\hline$\delta_{a, r}<\delta_{1}$ & Low Price Impression \\
\hline$\delta_{1} \leq \delta_{a, r} \leq \delta_{2}$ & Medium Price Impression \\
\hline$\delta_{a, r}>\delta_{2}$ & High Price Impression \\
\hline
\end{tabular}

Weights of Competitors. Traditional farming markets, large supermarkets and other e-commence suppliers are the mainly competitors of e-commence suppliers which engage in fresh goods business. The sales status of these three kinds of competitors influence the e-commence supplier in similar fresh goods, but the influence degree in different kinds of fresh goods is not the same, in other words, the weight value $\tau_{h, r}$ in function (1) varies with different kinds of fresh goods. This value can be determined by the sales achievements of fresh goods in e-commence supplier $a$.

E-commence supplier $a$ can divide the rank of fresh goods using the ABC classification. Divide these fresh goods into class A whose sales contribution degree is $75 \%$ in total, then the class B are those products whose total sales contribution degree is $20 \%$, and the last products are divided into class $C$, that means, the sales speed of products in class $A, B$ and $C$ is fast, middle and slow. Generally speaking, consumers are more sensitive on those sold fast, in other words, the consumers' sensitive degree of class A, class B and class C decreasing one by one. Hereby value the weight of competitors: give low impression competitors higher weight in those fresh goods sold fast, shown in table 2 .

Table 2 The Value Principle of Competitors' Price Impression

\begin{tabular}{|c|c|c|c|}
\hline Fresh Goods & Low & Medium & High \\
\hline Class A & $\sqrt{ }$ & & \\
\hline Class B & & $\sqrt{ }$ & \\
\hline Class C & & & $\sqrt{ }$ \\
\hline
\end{tabular}

In particular, products sold in traditional farming markets are mainly in middle or low price, so the traditional farming markets are low price impression competitors, large supermarkets are mainly medium price impression competitors, and products sold in other e-commence suppliers are similar to e-commence supplier $a$ in variety and grade, we divide them into medium or high price impression competitors. The determination of $\tau_{h, r}$ can reference the principle and determine by pricing specialists of e-commence supplier.

Therefore, after mastering the pricing information of competitors, e-commence suppliers can calculate the optimal price based on the competitors-referenced pricing method. 


\section{Analysis of Examples}

Fresh Goods ABC Analysis of E-commence Supplier $a$. We divide fresh goods sold in e-commence suppliers into 8 parts: fresh meat, leaf vegetables, fruits, cooked food, frozen seafood, raw milk, eggs and soybean products, the sales amount of fresh goods in e-commence supplier $a$ is shown in table 3 .

Table 3 Sales Amount of Fresh Goods in E-commence Supplier $a$

\begin{tabular}{|c|c|c|c|c|c|c|c|c|}
\hline Class & $\begin{array}{c}\text { Fresh } \\
\text { Meat }\end{array}$ & $\begin{array}{c}\text { Leaf } \\
\text { Vegetables }\end{array}$ & Fruits & $\begin{array}{c}\text { Cooked } \\
\text { Food }\end{array}$ & $\begin{array}{c}\text { Frozen } \\
\text { Seafood }\end{array}$ & $\begin{array}{c}\text { Raw } \\
\text { Milk }\end{array}$ & Eggs & $\begin{array}{c}\text { Soybean } \\
\text { Products }\end{array}$ \\
\hline $\begin{array}{c}\text { Sales Amount } \\
\text { [1000 RMB/Year] }\end{array}$ & 3.5 & 1 & 6.5 & 5 & 4 & 2 & 1.5 & 1.5 \\
\hline $\begin{array}{c}\text { Contribution Ratio } \\
{[\%]}\end{array}$ & 14.0 & 4.0 & 26.0 & 20.0 & 16.0 & 8.0 & 6.0 & 6.0 \\
\hline
\end{tabular}

Rely on ABC classification, the contribution ratio of fruits, cooked food, frozen seafood and fresh meat is $75 \%$ in total, so we divide these kinds of fresh goods into class A. The rate of raw milk, eggs and soybean products is $20 \%$ in total, so these products belong to class $\mathrm{B}$. The last products belong to class $\mathrm{C}$, that means, just leaf vegetables involved in class $\mathrm{C}$.

Competitors of E-commence Supplier $a$. In reality, the number of competitors in daily business of e-commence supplier $a$ is more than one. Base on function (2), calculating the value of $\delta_{a, r}$ and through the analysis of $\delta_{a, r}$, divide competitors into different kinds, shown in table 4.

Table 4 Division of Competitors Compete with E-commence Supplier $a$

\begin{tabular}{|c|c|}
\hline Value of $\delta_{a, r}$ & Competitor $r$ \\
\hline$\delta_{a, r}<-0.05$ & Low Price Impression \\
\hline$-0.05 \leq \delta_{a, r} \leq 0.05$ & Medium Price Impression \\
\hline$\delta_{a, r}>0.05$ & High Price Impression \\
\hline
\end{tabular}

In a certain period of operation, assuming the e-commence supplier a divides its competitors rely on table 4 , to show the numerical results, we chose traditional farming market $b$ in low price impression competitors, supermarket $c$ in middle price impression competitors and e-commence supplier $d$ in high price impression competitors to analyze and calculate, the value of $\delta_{a, r}$ shown in table 5 .

Table 5 Values of $\delta_{a, r}$

\begin{tabular}{|c|c|c|c|}
\hline Competitor & $b$ & $c$ & $d$ \\
\hline Value of $\delta_{a, r}$ & -0.1 & 0.01 & 0.12 \\
\hline
\end{tabular}

Based on the analysis above, one can draw conclusions following:

The demand for fruits, cooked foods, frozen seafood and fresh meat is largest, the the 
consumers' sensitive degree of them is higher, so e-commence supplier $a$ must be cautious about pricing these goods. And competitors in these kinds of fresh goods are mainly low price impression, such as traditional farming market $b$, thus, the weight of $b$ in function (1) should be max.

The demand for raw milk, eggs, soybean products is in the medium level, and the consumers' sensitive degree of them is also in the medium level, so when price these fresh goods, e-commence supplier $a$ must consider medium price impression competitors more, such as supermarket $C$, set its weight maximum.

The contribution ratio of leaf vegetables is minimum, therefore, when price this kind of fresh goods, e-commence supplier $a$ can refer to the price of e-commence supplier $d$, and set its weight maximum.

Then, value $\tau_{h, r}$ based on the above analysis, shown in table 6 .

Table 6 Values of $\tau_{h, r}$

\begin{tabular}{|c|c|c|c|}
\hline Class & $\begin{array}{l}b \quad \text { (Low Price } \\
\text { Impression })\end{array}$ & $\begin{array}{l}c \text { (Medium Price } \\
\text { Impression })\end{array}$ & $\begin{array}{l}d \text { (High Price } \\
\text { Impression) }\end{array}$ \\
\hline A & 0.5 & 0.3 & 0.2 \\
\hline B & 0.25 & 0.6 & 0.15 \\
\hline C & 0.1 & 0.2 & 0.7 \\
\hline
\end{tabular}

Determine the Upper Bound of Price. Take rapeseed, litchi, fresh pork and marinating bean curd cake as examples, giving the upper bound price of competitor $b, c$, and $d$ on a certain stage ( here the first stage is assumed), shown in table 7.

Table 7 Upper Bound Price of Competitor and E-commence Supplier a in Stage One

\begin{tabular}{|c|c|c|c|c|}
\hline & Rapeseed & Litchi & Fresh Pork & $\begin{array}{c}\text { Marinating Bean } \\
\text { Curd Cake }\end{array}$ \\
\hline$b$ & 2.0 & 10.0 & 26.0 & 14.9 \\
\hline$c$ & 3.2 & 18.2 & 30.2 & 19.4 \\
\hline$d$ & 6.8 & 32.8 & 48.0 & 28.0 \\
\hline$a$ & 5.0 & 16.7 & 31.7 & 19.3 \\
\hline
\end{tabular}

Therefore, we can calculate the upper bound of fresh goods in e-commence supplier $a$ based on values of $\delta_{d, r}$ (in table 5) and $\tau_{h, r}$ (in table 6) in stage one, that is the optimal price $\left(\omega_{1}^{*}\right)$ of e-commence supplier $a$ in stage one, shown in table 7.

\section{Conclusion}

In this paper, we established the pricing strategy and through analysis of example to show 
the numerical results based on the competitors-referenced pricing model. This pricing method is guided by the competition in fresh goods, we adopt this method concerning the fierce competition of e-commence suppliers engaged in fresh goods business in China. In fact, this price is not necessarily can make e-commence suppliers gain maximum profits, but to be able to gain a competitive advantage. E-commence suppliers also need to consider the demand, balance competition and demand in price decision.

\section{Acknowledgment:}

Social Science Research Project of Colleges and Universities in Shandong Province (Project Number: J15WB70)

\section{References}

[1]J.L.Ding. Analysis and Design of Operation Mode on Fresh Agricultural Products in E-commence[J]. Fujian Diannao,2014(11):161-163.

[2]Chan,L.M.A,Z.J.M.Shen,D.Simchi-Levi, et al. Coordination of pricing and inventory decisions: a survey and classification[M]//D. Simchi-Levi, S.D.Wu, Z.J.Shen. Handbook of Quantitative Supply Chain Analysis: Modeling in the E-Business Era. Boston:Kluwer Academic Publishers, 2004.

[3]Yano, C. and S. M. Gilbert. Coordinated pricing and production/procurement decisions: a review[M]//A.K.Chakravarty,J.Eliashberg. Managing Business Interfaces: Marketing,

Engineering and Manufacturing Perspectives. Norwell: Kluwer Academic Publishers, 2003.

[4]J.K, GIGLER, EMT HENDRIX, RA HEESEN, HEESSN, et al. On optimisation of agri chain by dynamic programming.European Journal of operational Research, 2002(139):613-625.

[5]L.Wang, B.Dan. Study on Fresh and Pricing of Fresh Agricultural Products Based on Consumer Choice Behavior[J].Journal of Management,2014(4):449-454.

[6]L.Tang, L.D.Zhao, Y.D.Zhang. Multi-stage Pricing Model and Algorithm of Fresh Food[J]. Systems Engineering-Theory Methodology Application.2010(2):140-146+151.

[7]Y.J.Lu.Study on Dynamic Pricing on Fresh Vegetables in Supermarkets in China[D].Beijing:Beijing Jiaotong University, 2010.

[8]F.Wang. Study on Dynamic Pricing on Fresh Food in Supermarkets[D]. Nanjing: Southeast University, 2006. 